\title{
Simulation of gravel-sand bed response to flushing flows using a two-fraction entrainment approach: Model development and flume experiment
}

\author{
Fu-Chun $\mathrm{Wu}$ \\ Department of Bioenvironmental Systems Engineering and Hydrotech Research Institute, National Taiwan University, \\ Taipei, Taiwan \\ Yi-Ju Chou \\ Department of Bioenvironmental Systems Engineering, National Taiwan University, Taipei, Taiwan \\ Received 19 March 2003; revised 27 April 2003; accepted 19 May 2003; published 14 August 2003. \\ [1] In this work we combine existing ideas on gravel and sand entrainment into a \\ simulation model for flows that flush sand from the surface and subsurface of a gravel \\ riverbed. A flume experiment is conducted to provide a test of the flushing model. The \\ primary advance represented in this paper is incorporation of a two-fraction entrainment \\ approach into a routing model to account for the effect of sand content on the entrainment \\ and transport of bed sediment, which is crucial for simulation of the flushing process \\ associated with progressively decreasing sand proportions. A combination of the active \\ layer concept and two-layer treatment is adopted herein to outline the framework of \\ sediment transport system, which allows incorporation of subsurface sand into the surface \\ layer through the mechanisms of upward entrainment and bed degradation. Sediment \\ routing computations are executed in two steps: in the first step, the change of bed level is \\ computed with the continuity equation of sediment in the surface layer; in the second step, \\ the changes of sediment storage in the surface and subsurface layers are calculated with the \\ mass conservations of sediment. An important finding of this study is that the flume \\ results could not be adequately simulated without an upward sand flux from the \\ subsurface, which confirms the operation of a process that has only been hypothesized. \\ The simulation results, including the evolutions of bed composition and elevation, are in \\ good agreement with the observations, implying a potential application of the proposed \\ model in determining flushing flows for environmental benefit. INDEX TERMS: 1815 \\ Hydrology: Erosion and sedimentation; 1824 Hydrology: Geomorphology (1625); 1860 Hydrology: Runoff \\ and streamflow; 1894 Hydrology: Instruments and techniques; KEYWORDS: flushing flow, gravel-sand bed, \\ entrainment, sediment transport, model simulation, flume experiment
}

Citation: Wu, F.-C., and Y.-J. Chou, Simulation of gravel-sand bed response to flushing flows using a two-fraction entrainment approach: Model development and flume experiment, Water Resour. Res., 39(8), 1211, doi:10.1029/2003WR002184, 2003.

\section{Introduction}

[2] The ecoenvironmental impacts of river regulation have been the focus of extensive studies for more than two decades, yielding a vast amount of literature that documents the research results and worldwide case studies [e.g., Ward and Stanford, 1979; Petts, 1984; Costa et al., 1995; Bradley and Smith, 1984; Walker and Thoms, 1993; Wu and Wang, 2002]. Among the most well known effects of river impoundments is the alteration of flow and sediment regimes in the channels downstream of the dams [Williams and Wolman, 1984]. For such channels, the flow magnitude and sediment transport capacity are typically reduced. The upstream supply of coarse sediment (such as gravel) is eliminated by reservoir trapping, whereas fine sediment (such as sand) may be introduced to these channels either from the downstream tributaries or from the

Copyright 2003 by the American Geophysical Union. 0043-1397/03/2003WR002184\$09.00 reservoirs [Wilcock et al., 1996b; Collier, 2002]. In particular, a variety of natural and anthropogenic processes (e.g., landslide, fire, logging, and land development) taking place in the tributary subbasins can further increase the supply of fine sediment to a gravel-bed river. As a consequence of the increased sand input yet the reduced transport capacity in the downstream channel, the excess amount of sand will be deposited and accumulated in the interstices of the gravel substrate. The intrusion of fine sediment into gravel beds was extensively reported to have caused adverse effects on stream ecosystem, such as the declines in aquatic habitat and the degraded quality of salmonid spawning gravels (e.g., reviewed by Reiser [1998] and $W u$ [2000]).

[3] For mitigating these impacts, controlled releases of flushing flow are designed to mimic the action of natural floods in removing the accumulated fine sediments from the channel and loosening the gravel bed [Kondolf and Wilcock, 1996]. Planning of flushing flows involves determination of the magnitude, duration, and timing of the flow release 
[Reiser et al., 1989]. Wilcock et al. [1996b] claimed that accurate specification of flushing flows is often hindered by the complexity of the flow and transport system as well as the sparse data typically available. The main characteristic of such a system is that the proportion of sand in the bed is transient in nature given that bed sand content progressively decreases over time during the flushing flow release. The decline in sand proportion modifies the sand and gravel transport rates through its influences on the thresholds for incipient motion and the availability of sediment in bed surface [Wilcock, 1998; Wilcock et al., 2001], making this flow-transport system a highly dynamic one. Thus, for effective planning of the flushing flows, an appropriate sediment routing algorithm is demanded to realistically simulate the system evolution.

[4] Numerical models are potentially powerful tools for investigating the temporal variations of river channels. Over the past decades, a number of models have been developed to address riverbed evolutions such as the degradation, armoring [e.g., Rahuel et al., 1989; Parker and Sutherland, 1990; Holly and Rahuel, 1990a, 1990b], aggradation, and downstream fining [e.g., van Niekerk et al., 1992; Hoey and Ferguson, 1994; Cui et al., 1996]. These models use widthaveraged representations of channel hydraulics, fractional bed load transport rates, and degradation or aggradation in an iterative computational scheme involving a combination of the sediment continuity and transport equations. At each time step, the bed level and grain size distribution are updated and thus the textural stratigraphy of bed material is also estimated [Ferguson et al., 2001]. On the other hand, Wilcock et al. [1996b] developed a simplified two-part sediment routing algorithm to evaluate the removal of sand from a gravel bed by the flushing flow. However, the dependence of sediment entrainment thresholds on sand content and the degradation of channel bed were not considered in this simplified model.

[5] The aim of this study is to develop a sediment routing model used for simulation of the gravel-sand bed response to flushing flows. Such a model should take into consideration the effect of sand content on the transportability of bed sediments. The model results should keep track of the system evolutions associated with the flushing process, in terms of bed composition, bed elevation, and sediment transport rates. To this end we employ a two-fraction entrainment approach to quantify the relations between critical shear stress and surface sand proportion. An active two-layer framework is adopted to account for the interactions of sediment between bed surface and subsurface. We also carry out an experimental study to provide a test of the proposed flushing model.

\section{Two-Fraction Entrainment Approach}

[6] The key element of a sediment routing algorithm used to simulate the dynamic response of a gravel-sand bed to the flushing flow is the quantitative relation for bed load transport that incorporates the effect of sand content on the incipient motion of bed sediment [Lisle et al., 2000; Wilcock et al., 2001]. In this study, a two-fraction entrainment approach [Wilcock, 1998] was adopted for this purpose because it provides a simplified but practical means to predict the entrainment thresholds of the fine and coarse portions of the bed material. This approach divides the bed

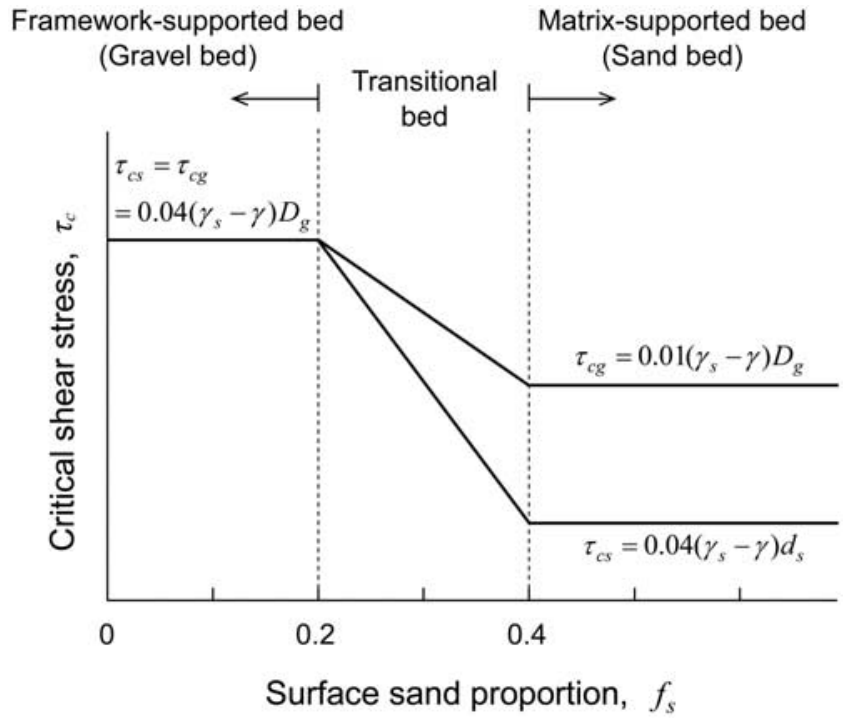

Figure 1. Variations of critical shear stress with surface sand proportion for the gravel and sand fractions. For the framework-supported bed $\left(f_{s}<0.2\right)$ and matrix-supported bed $\left(f_{s}>0.4\right)$, critical shear stresses remain constant. Linear variations of critical shear stress occur in the transitional region $\left(0.2 \leq f_{s} \leq 0.4\right)$.

sediment into only two size fractions, i.e., sand $(<2 \mathrm{~mm})$ and gravel $(>2 \mathrm{~mm})$. Since the focus of this study is on the removal of fine sediment from the coarse-grained bed, the two-fraction approach is considered more suitable than the conventional treatment of bed material as the oversimplified single-sized sediment or impractical number of size fractions for which available data are typically sparse. The definition of the size ranges for sand $(<2 \mathrm{~mm})$ and gravel $(2-64 \mathrm{~mm})$ has been widely used as a common standard [e.g., Habersack and Laronne, 2001; Collier, 2002]. The following is a summary of the two-fraction entrainment approach presented in the earlier work [Wilcock, 1998].

[7] Variations of the critical shear stresses for sand and gravel, $\tau_{c s}$ and $\tau_{c g}$, with the proportion of sand in the bed surface, $f_{s}$, are constrained by the limiting values given below. The empirical values of $\tau_{c s}$ for a purely sand bed $\left(f_{s}=1\right)$ and $\tau_{c g}$ for a purely gravel bed $\left(f_{s}=0\right)$ were known for the well-sorted sediment, for which the critical Shields stress $\tau^{*}{ }_{c}$ was found to be $\sim 0.04$ for grain sizes $>\sim 0.5 \mathrm{~mm}$. According to the definition of $\tau^{*}{ }_{c}$, one obtains $\tau_{c s}=0.04\left(\gamma_{s}-\gamma\right) d_{s}$ for $f_{s}=1$ and $\tau_{c g}=0.04\left(\gamma_{s}-\gamma\right) D_{g}$ for $f_{s}=0$, where $\gamma_{s}$ and $\gamma=$ specific weights of sediment and water, respectively; $d_{s}$ and $D_{g}=$ median sizes of sand and gravel fractions, respectively. On the other hand, values of $\tau_{c s}$ for $f_{s} \rightarrow 0$ and $\tau_{c g}$ for $f_{s} \rightarrow 1$ are determined by the interactions between these two fractions. As $f_{s} \rightarrow 0$, entrainment of the sand requires initial movement of the gravel, thus $\tau_{c s}=\tau_{c g}$ may be expected. As $f_{s} \rightarrow 1$, flume observations have indicated a minimum value of $\tau^{*}{ }_{c g} \approx$ 0.01 , leading to $\tau_{c g}=0.01\left(\gamma_{s}-\gamma\right) D_{g}$. It is illustrated in Figure 1 that the limiting values of critical shear stress are valid for the region identified as framework-supported bed (i.e., $\left.f_{s}<0.2\right)$ or matrix-supported bed (i.e., $f_{s}>0.4$ ). For $f_{s}<0.2$, the channel bed is composed of an interlocked gravel framework; at $f_{s} \geq 0.2$, individual framework 


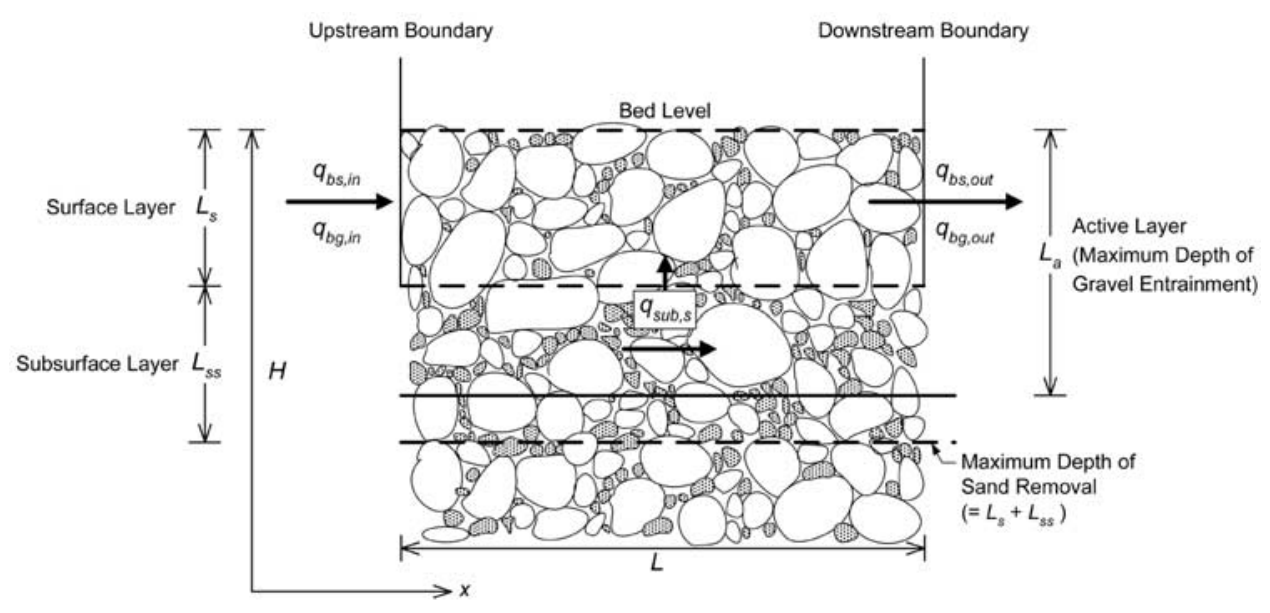

Figure 2. Definition sketch showing the surface layer, subsurface layer, active layer, bed load transport, and upward sand entrainment in the bed of a channel reach.

gravels begin to lose contact; for $f_{s}>0.4$, the gravel framework is replaced by a sand matrix with interbedded gravels. In the transitional region $0.2<f_{s}<0.4$, both $\tau_{c s}$ and $\tau_{c g}$ decrease with the increase of $f_{s}$. The compiled data [see Wilcock, 1998] appear to indicate that the decreasing trends of $\tau_{c s}$ and $\tau_{c g}$ within the transitional region may well be represented by linear approximations, with the gradient of $\tau_{c s}$ steeper than that of $\tau_{c g}$. The two-fraction entrainment approach presented in Figure 1 can be used to evaluate $\tau_{c s}$ and $\tau_{c g}$ corresponding to decreasing values of $f_{s}$ at different stages of the flushing process. The values of $f_{s}, \tau_{c s}$, and $\tau_{c g}$ are then used to calculate the transport rates of sand and gravel fractions (discussed in Section 4.3).

\section{Modeling Depth Flushing}

[8] To develop a sediment routing algorithm for simulation of the gravel-sand bed response to flushing flows, it is necessary to first identify the sediment transport process to be modeled. According to the degree of gravel entrainment, the flushing process can be classified as surface or depth flushing [Reiser et al., 1989; Kondolf and Wilcock, 1996]. Surface flushing removes sand from bed surface without entraining the gravel; whereas depth flushing involves entrainment of surface gravels and thus permits removal of subsurface fine sediment. Depth flushing is usually implemented prior to the spawning season for removal of excess sand from channel bed, while surface flushing may be implemented in the incubation period to prevent accumulation of fine sediment in the bed surface [Milhous, 1998; Wu, 2000]. Because of the sand removal efficiency associated with the depth flushing, the sediment routing model developed in this study is aimed to simulate this type of flushing process. The model components are described in the subsequent sections.

\subsection{Active Two-Layer Framework}

[9] Here, based on previous field/laboratory observations, we present a hypothetical framework for modeling the depth flushing process. The active two-layer framework is a combination of the active layer concept [Hirano, 1971] and two-layer treatment [Wilcock et al., 1996b], the latter divides the uppermost part of the gravel-sand bed into a surface layer (thickness $L_{s}$ ) and a subsurface layer (thickness $\left.L_{s s}\right)$, as depicted in Figure 2. Following the two-layer treatment [Wilcock et al., 1996b], $L_{s}$ is assumed as the depth to which fine sediment could be flushed with no gravel entrainment, the bottom of the subsurface layer is set at the maximum depth that could be flushed with active gravel entrainment. The maximum depth of gravel entrainment is defined here as the active layer thickness, $L_{a}$ (see Figure 2). The definitions of $L_{s}, L_{s s}$, and $L_{a}$ given here are primarily for the purpose of numerical modeling. According to laboratory and field observations [Beschta and Jackson, 1979; Diplas and Parker, 1985; Wilcock et al., 1996b], sand removal can proceed more deeply than gravel entrainment, i.e., the maximum flush depth, $L_{s}+L_{s s}$, is slightly greater than $L_{a}$ (as shown in Figure 2), which is discussed below.

[10] Introduction of an active layer allows generalization of the sediment continuity equation to mixtures of grain sizes for the correct accounting of sediment transport, bed level variation, and development of bed stratigraphy [Parker et al., 2000]. As mentioned earlier, Wilcock et al. [1996b] did not include an active layer in their sediment routing algorithm because negligible bed degradation was observed at their study site. However, to simulate the gravel-sand bed response to large flows that may cause considerable bed degradation, here we incorporate an active layer into the two-layer treatment because of its simplicity for applications. Herein the conventional active layer is revised as the maximum depth of gravel entrainment such that it is compatible with the framework of depth flushing. This revised definition of active layer is plausible given that the limit value of $L_{s}=1.7 D_{84}$, estimated from local observations by Wilcock et al. [1996a], is very close to twice of $d_{84}$ of the bed material, which is the thickness of active layer used by Hoey and Ferguson [1994]. The surface layer thickness $L_{s} \approx D_{84}$ of the framework gravels, modified from $d_{90}$ of the entire bed material that was used by Wilcock et al. [1996b], is similar to the observed thickness of armor layer [Proffitt, 1980]. The maximum depth of sand removal, $L_{s}+L_{s s}$, is taken to be $2 D_{84}$, as suggested by Wilcock et al. [1996b], implying that $L_{s}+L_{S S}$ is greater than $L_{a}$ by an amount of $0.3 D_{84}$.

[11] The thickness $L_{s}, L_{s s}$, and $L_{a}$ are assumed to remain invariant for the entire course of simulation. Thus, as the 
bed level is degraded by an amount of $\Delta H$, the surface, subsurface, and active layers are all shifted downward by $\Delta H$. This downward shift makes it possible to incorporate subsurface sediment into the surface layer, and underneath substrate sediment into the subsurface layer at a rate proportional to bed degradation. Bed load transport mainly takes place in the surface layer, as demonstrated in Figure 2. The subsurface sediment, once incorporated into the surface layer, can be transported as bed load. Although gravel entrainment reaches to a depth of $L_{a}$, it is assumed that the movement of sediment below the surface layer does not contribute much to the bed load, primarily due to the much lower frequency of gravel entrainment in the subsurface layer. Nonetheless, Wilcock et al. [1996b] hypothesized that the entrainment of subsurface gravel would produce an upward sand flux from the subsurface, which is illustrated in Figure 2 as $q_{s u b, s}$ and discussed in the following.

\subsection{Upward Sand Entrainment from Subsurface}

[12] The upward entrainment rate of subsurface sand is dependent upon the mean frequency of gravel entrainment in the active layer, which determines the mean frequency with which subsurface fine sediment is subjected to the flow. Wilcock et al. [1996b] used this approach to account for the removal of subsurface sand. The mean frequency of gravel entrainment in the active layer can be represented by a timescale estimated for the duration producing spatially complete gravel entrainment, defined as the exchange time $t_{\text {ex }}$ [Wilcock et al., 1996b]. Values of $t_{\text {ex }}$ vary inversely with the flow discharge. As such, the higher frequency of gravel entrainment corresponding to a larger flow leads to a smaller value of $t_{\text {ex }}$ yet a greater upward sand flux. Furthermore, the upward sand entrainment rate is also dependent upon the difference between subsurface and surface sand proportions. The net upward flux with which sand is entrained from the subsurface may be expressed as

$$
q_{s u b, s}=C_{u}\left(\frac{f_{s s}-f_{s}}{f_{s s}}\right) \frac{M_{s s}}{t_{e x}}
$$

where $q_{s u b, s}$ is upward sand flux from the subsurface (mass/ area/time); $f_{s}$ and $f_{s s}$ are proportions of sand in the surface and subsurface layers, respectively; $M_{s s}$ is mass of sand in the unit-area (i.e., unit width and length) subsurface layer; the upward entrainment constant $C_{u}$ is taken to be 0.5 [Wilcock et al., 1996b]. Note that (1) is only valid for $f_{s s}>f_{s}$, the upward sand flux remains as zero for $f_{s s} \leq f_{s}$. Although (1) was verified with limited data, it provides a simple, reasonably constrained, and testable estimate of the upward sand entrainment from subsurface. As will be shown in section 6.2, this upward sand flux plays an important role in the removal of subsurface sand.

\subsection{Sediment Routing Algorithm}

[13] Sediment routing computations are based on the mass conservation of sediment in both the surface and subsurface layers. For a unit-width channel reach of length $L$ (Figure 2), the total input of sediment to the surface layer in a time step $\Delta t$ is the sum of upstream bed load inflow and subsurface sand supply. The former is evaluated by $\left(q_{b s, i n}+\right.$ $\left.q_{b g, \text { in }}\right) \Delta t$, where $q_{b s, \text { in }}$ and $q_{b g, \text { in }}$ are sand and gravel transport rates (mass/width/time) from upstream, while the latter can be expressed as $q_{s u b, s} L \Delta t$. Similarly, the total output of sediment from the surface layer is equal to the sum of sand and gravel outflows, as evaluated by $\left(q_{b s, o u t}+q_{b g, \text { out }}\right) \Delta t$, where the fractional transport rates, $q_{b s, \text { out }}$ and $q_{b g, \text { out }}$, are known to vary with the $f_{s}$ value of this reach. The sediment outflow from a channel reach is in fact the sediment inflow to the immediately downstream reach. The difference between the total sediment input and output is the change of sediment storage in the surface layer of a channel reach. Sediment routing computations are executed in two steps: the first step is to compute the change of bed level (i.e., aggradation or degradation); the second step is to update the bed composition (i.e., surface and subsurface sand proportions). These two steps are described below.

[14] In the first step, the change of bed level is computed with the continuity equation of sediment in the surface layer:

$$
(1-\lambda) \frac{\partial H}{\partial t}=\frac{1}{\rho_{s}}\left(-\frac{\partial q_{T}}{\partial x}+q_{s u b, s}\right)
$$

where $H$ is bed level elevation (as shown in Figure 2); $\lambda$ is porosity of the surface layer; $\rho_{s}$ is density of sediment; $q_{t}$ is total bed load transport rate (see below for details); $x$ is distance in the streamwise direction; and $t$ denotes time. The finite-difference form of (2) for a channel reach $L$ can be expressed as

$$
\Delta H=\frac{\Delta t}{L(1-\lambda) \rho_{s}}\left[\left(q_{T, \text { in }}-q_{T, \text { out }}\right)+L q_{\text {sub }, s}\right]
$$

where $\Delta H$ is change of bed elevation in a time step $\Delta t$. Given the distinctly different structures of the frameworkand matrix-supported beds, different expressions for $\lambda, q_{T}$, and $q_{s u b, s}$ must be used to separately deal with these bed structures. For $f_{s}<0.2$, the sand grains partially fill in the interstices between the interlocked gravels and thus have little effect on the change of bed elevation. The bed level variation is governed by the change of gravel storage in the surface layer. In this case, $\lambda=n_{g}=$ porosity of the framework gravels, $q_{T, \text { in }}=q_{b g, \text { in }}, q_{T, \text { out }}=q_{b g, \text { out }}$, and $q_{s u b, s}$ is taken to be zero. However, for $f_{s} \geq 0.2$, the framework gravels lose contact, variation of bed elevation is thus determined by the change of total sediment storage (including sand and gravel) in the bed surface. In this case, the porosity varies as a function of sand proportion, i.e., $\lambda=$ $n_{s} f_{s} /\left[1-n_{s}\left(1-f_{s}\right)\right]$, where $n_{s}$ is porosity of the sand matrix, $q_{\text {T,in }}=q_{b s, \text { in }}+q_{b g, \text { in }}, q_{T, \text { out }}=q_{b s, \text { out }}+q_{b g, \text { out }}$, and $q_{s u b, s}$ is simply the value determined from (1). As stated earlier, when the bed level is lowered (or raised) by an amount of $\Delta H$ due to degradation (or aggradation), the boundaries of the surface and subsurface layers must be shifted downward (or upward) accordingly.

[15] In the second step, the changes of sediment storage in the surface and subsurface layers are computed with the mass conservations of sediment. The difference between upstream bed load inflow and downstream bed load outflow is evaluated using the existing $f_{s}$ values. Meanwhile, the upward sand entrainment, $q_{s u b, s} L \Delta t$, is added to the storage of sand in the surface layer but removed from the storage of sand in the subsurface layer. In addition, given the bed level change $\Delta H$ (evaluated in the first step), the quantities of sand and gravel in the shifted surface and subsurface layers 


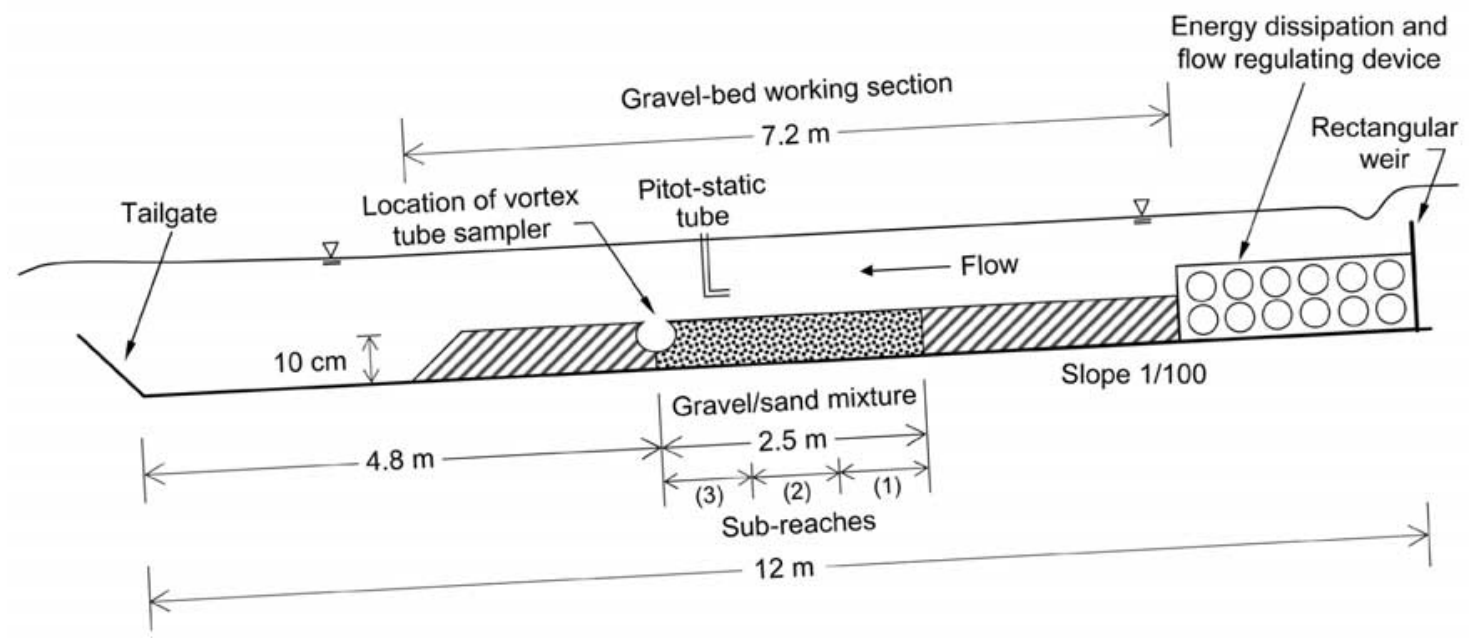

Figure 3. Schematic diagram of the testing flume and experimental setup.

need to be recalculated due to the incorporations of subsurface sediment into the surface layer and also the underneath substrate into the subsurface layer. The corresponding $f_{s}$ and $f_{s s}$ values are updated at the end of each time step.

\section{Flume Experiments}

\subsection{Overview}

[16] To provide a test of the proposed sediment routing model, an experimental study was conducted for observing the evolutions of bed composition and elevation. The experiments were carried out in a 40-cm-wide and 12-mlong flume with glass sidewalls (Figure 3), located at Hydrotech Research Institute, NTU. An upstream rectangular weir was used for flow measurements. Immediately downstream of the weir was an energy dissipation and flow regulating device. An adjustable tailgate at the downstream end was used to maintain a quasi-uniform flow (confirmed with two point gauges) in the 7.2-m-long working section paved with 10 -cm-thick gravels $(=\sim 4$ times the surface layer thickness). The middle portion of the working section could be replaced with a $2.5-\mathrm{m}-$ long gravel/sand mixture reach for the flushing flow test. The slope of the flume was adjusted to $1 / 100$, a typical value for mountain gravel-bed rivers [Wohl, 2000].

[17] The sand and gravel used in the experiments were prepared by mixing the sediments of different size classes. As shown in Figure 4, grains of three size ranges covering $0.5-2 \mathrm{~mm}$ were mixed in the ratio $1: 2: 1$ to form the sand fraction, whereas grains of five size ranges covering 2$50.8 \mathrm{~mm}$ were mixed in the ratio $1: 2: 3: 2: 1$ to form the gravel fraction. The distribution of each size class was roughly defined by $1 / 3 \phi$ size range. The sand fraction was mainly composed of light-colored grains, which made it easy to visually distinguish sand from gravel. As can be seen from Figure 5b, the median sizes of sand and gravel fractions were $d_{s}=1.3 \mathrm{~mm}$ and $D_{g}=12 \mathrm{~mm}$, respectively; $D_{84}$ of the gravel fraction was $26 \mathrm{~mm}$. The specific gravity of sediment was 2.65. The porosities of sand and gravel were 0.2 and 0.33 , respectively. The low porosity of sand was attributed to the poorly sorted material. Differences in the results would be expected if different types or size distributions of sediments were used, because the median grain sizes and porosities resulting from the different materials might substantially change the critical shear stresses and bed structure, respectively, and thus the bed load transport and bed level elevation. By adding different amounts of sand to the bulk gravels, the gravel/sand mixtures with different sand proportions could be made. For example, Figure 5a illustrates the grain size distribution of a sediment mixture with sand proportion equal to 0.32 , produced by mixing sand and gravel in the mass ratio 32:68.

\subsection{Bed Shear Stress}

[18] To predict the bed load transport rate for a given flow discharge, we need a quantitative relation between bed shear stress $\tau_{0}$ and flow discharge $Q$. Bed shear stress $\tau_{0}$ can be evaluated with the logarithmic profile of the near-bed flow velocity. Nikora et al. [2001] investigated the distribution of temporally and spatially averaged flow velocity over gravel beds and concluded that the near-bed region can be subdivided into two layers, namely, the roughness layer in which the flow velocity is linearly distributed, and the logarithmic layer in which the velocity follows a logarith-

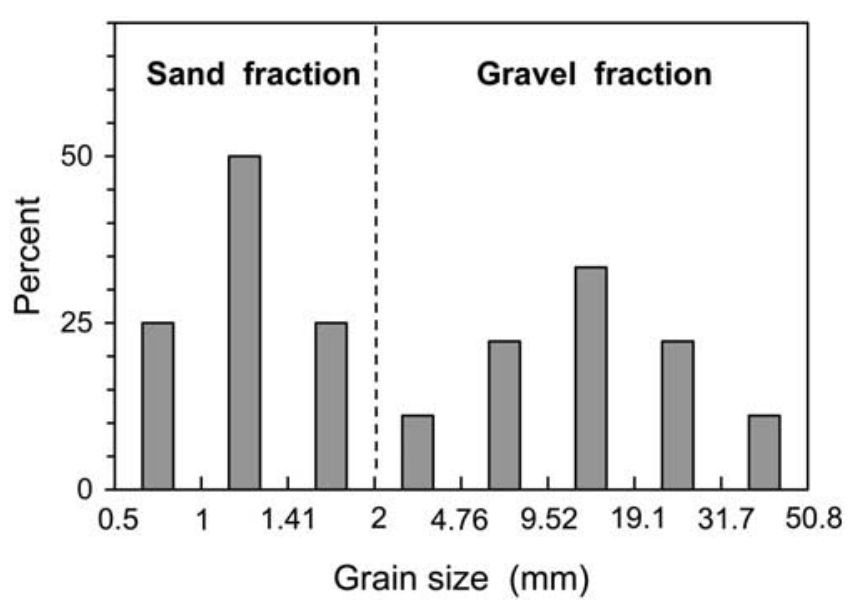

Figure 4. Histogram of the grain size for the sand and gravel fractions. Sand fraction covers three size ranges between 0.5 and $2 \mathrm{~mm}$; gravel fraction covers five size ranges between 2 and $50 \mathrm{~mm}$. 


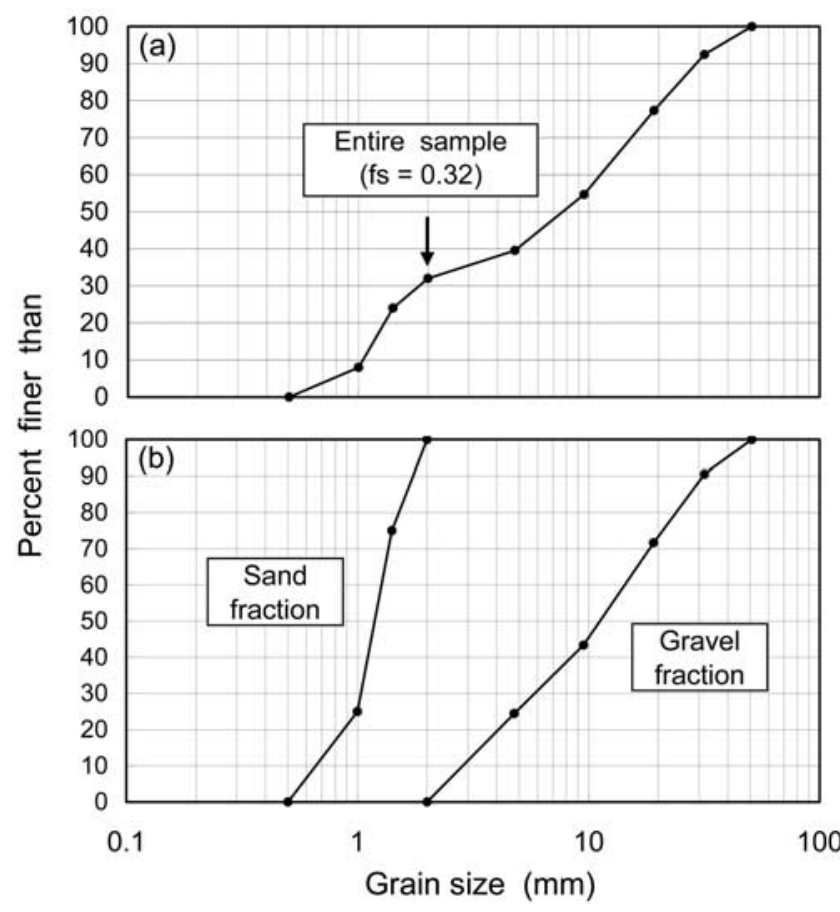

Figure 5. Cumulative grain size distributions. (a) Entire size distribution (sand proportion of the sample $=0.32$ ); (b) fractional size distributions truncated at $2 \mathrm{~mm}$ boundary.

mic variation. The linear layer covers the interfacial region between bed and flow, while the logarithmic layer covers the region $2 \Delta<z<5 \Delta$, where $z=$ elevation from the bed level (measured from the top of the bed surface), and the roughness height $\Delta \approx D_{g}$ for a rough permeable bed [Raupach et al., 1991; Nezu and Nakagawa, 1993].

[19] To examine the subdivisions of flow region, point velocities were measured with a Prandtl pitot-static tube (I.D. $1.4 \mathrm{~mm}$, O.D. $4 \mathrm{~mm}$, horizontal length $6.5 \mathrm{~cm}$, which could be placed very close to the bed surface) [Miller, 1996] throughout the depth of water $(=0.22 \mathrm{~m}$, for $Q=$ $0.053 \mathrm{~m}^{3} / \mathrm{s}$ ) over a gravel bed (Figure 3 ). The location of velocity measurements was carefully selected to ensure a fully developed turbulent boundary layer and avoid the backwater effect. The measured point velocities, multiplied by the corresponding flow area, were summed up over the entire depth of water to reconfirm with the discharge evaluated with the weir-flow rating curve. The measurement results revealed that flow velocity was linearly distributed for $z<0.02 \mathrm{~m}$; while in the region $0.02 \mathrm{~m}<$ $z<0.06 \mathrm{~m}$ (consistent with the abovementioned logarithmic region), the variation of velocity with elevation was found to follow the log law, i.e.,

$$
u=\frac{u *}{\kappa}\left(\ln z-\ln z_{0}\right)
$$

where $u$ is flow velocity at elevation $z ; u *$ is bed shear velocity equal to $\sqrt{\tau_{0} / \rho}, \rho$ is density of water; $\kappa=$ von Karman constant, taken to be 0.4 for clear water; $z_{0}=\mathrm{a}$ virtual zero-velocity elevation. As implied by (4), $u_{*}$ (or $\tau_{0}$ ) and $z_{0}$ can be evaluated with the slope and interception of the semi-logarithmic best fit line to the measured velocity distribution [Wilcock, 1996]. The same procedure was repeated for the other three low to medium flows $(0.005-$ $0.03 \mathrm{~m}^{3} / \mathrm{s}$ ) yielding a fairly consistent estimate of $z_{0}=$ $2.5 \mathrm{~mm}$, which is nearly equivalent to the recommended estimates of $z_{0}$, such as $0.095 d_{90}$ [Wilcock et al., 1996a] and $0.1 d_{84}$ [Whiting and Dietrich, 1990]. Once $z_{0}$ was determined, $\tau_{0}$ could be evaluated directly with (4) using a single velocity measured at the midpoint $(z=0.04 \mathrm{~m})$ of the logarithmic layer. Additional six flows ranging from 0.02 up to $0.07 \mathrm{~m}^{3} / \mathrm{s}$ were used altogether to derive the following regression equation $\left(R^{2}=0.98\right)$ :

$$
\tau_{0}=150 Q+3.1
$$

where $\tau_{0}$ is in $\mathrm{Pa} ; Q$ is in $\mathrm{m}^{3} / \mathrm{s}$. The maximum bed shear stress associated with the largest flow tested was $\sim 13.6 \mathrm{~Pa}$, which has been observed to produce sufficient entrainment of gravels in the bed surface and subsurface.

\subsection{Bed Load Equations}

[20] The predictive relations that express the gravel and sand transport rates as a function of flow discharge and surface sand proportion were established with the bed load data taken from the flume experiments. A vortex tube trap sampler was constructed for bed load measurements because of its sampling efficiency [Robinson, 1962; Milhous, 1973; Tacconi and Billi, 1987; Julien, 1998]. We designed this vortex tube trap bed load sampler following the criteria and recommendations provided in the previous literature. Figure 6 is an overview of the bed load sampler and a demonstration of this device installed in the flume. The width of the bed load sampler was $40 \mathrm{~cm}$ (to match with the flume width), including a 34-cm-wide portion of vortex tube trap and a 6-cm-wide frame for the sediment collector. The height of the sampler $(=10 \mathrm{~cm})$ was identical with the thickness of the gravel bed. The diameter of the vortex tube was $5 \mathrm{~cm}$; the trap opening was $4 \mathrm{~cm}$ wide, which allowed sampling of the coarsest sediment. The length of the sampler was $45.4 \mathrm{~cm}$, including a 25.4-cm-long portion of vortex tube trap and two $10-\mathrm{cm}$-long wings on both sides. The wings could be inserted into the gravel bed for stabilization. The angle of orientation between the vortex tube and flow direction was $60^{\circ}$, a value adopted by Milhous [1973] in his field studies. The $6-\mathrm{cm}$-wide by $25.4-\mathrm{cm}$-long sediment collector, with a side hole slightly larger than the vortex tube diameter, could be placed into the frame and replaced for each experimental run. The bed load sampler was made of acrylic material; the surface at the top was roughened to minimize the effect of a sudden transition in bed roughness. The bed load sampler was installed at $4.8 \mathrm{~m}$ upstream of the tailgate (Figure 3), where the backwater effect was negligible. Immediately upstream of the bed load sampler was a gravel/sand mixture section.

[21] To establish the bed load equations, sediment transport experiments were carried out with three different bed mixtures, each of which was subjected to at least four different flows. The bed conditions included $f_{s}=0.07$, 0.25 , and 0.32 ; the former was a typical frameworksupported bed containing very rare sand, the latter two were transitional beds composed of intermediate and abundant fine sediment, respectively. The two greater values of $f_{s}$ given above (i.e., 0.25 and 0.32 ) were the values of sand content for the mixtures (which were confirmed with the samples taken from bed surface), while the smallest one 


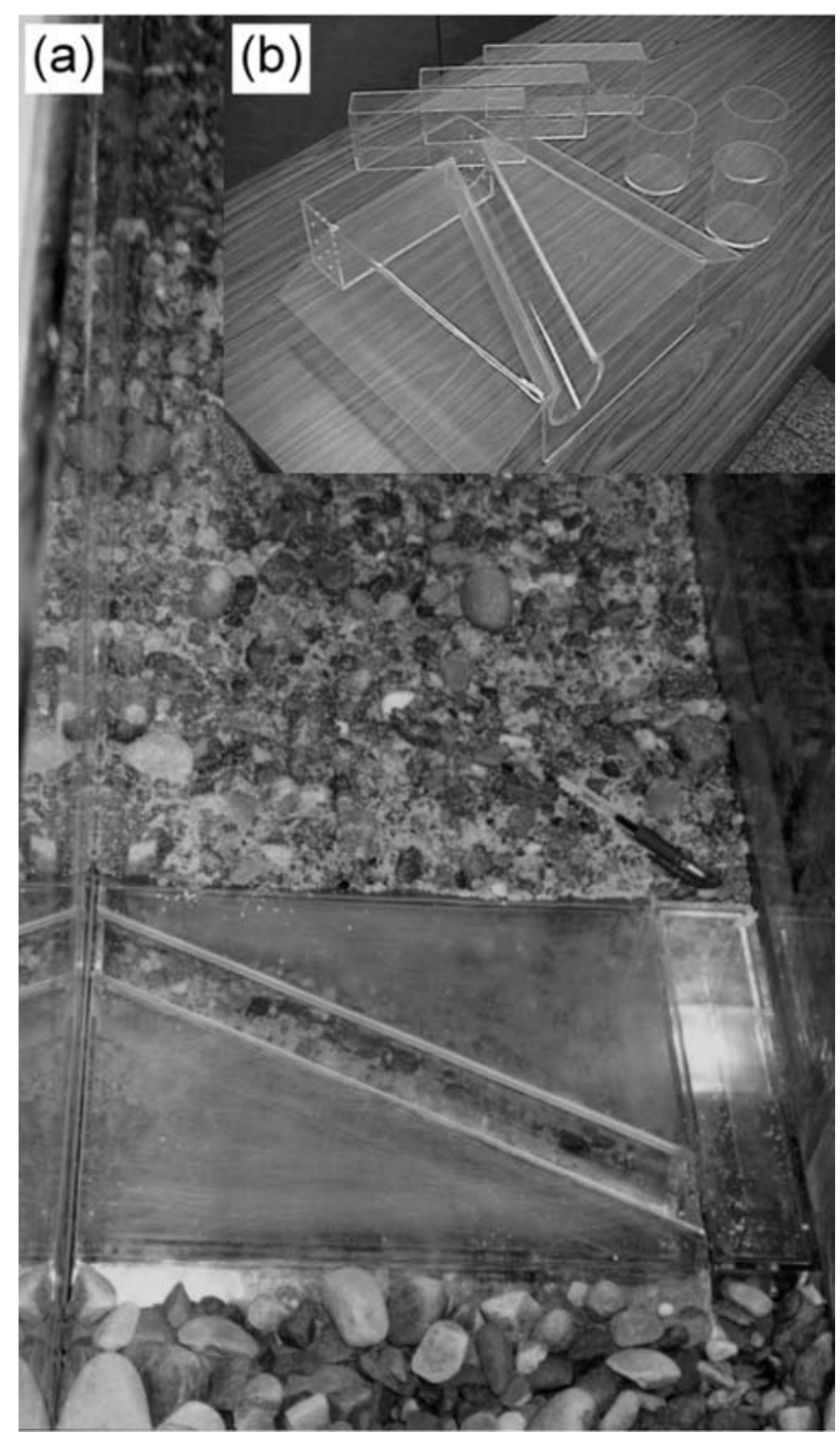

Figure 6. (a) Demonstration of the vortex tube trap sampler installed in the channel bed (looking into upstream of the flume). Immediately upstream of the bed load sampler was a gravel/sand mixture reach. The ball pen shown in the picture is $15 \mathrm{~cm}$ long. (b) Overview of the vortex tube trap sampler, sediment collectors, and bed material sampling cylinders. See color version of this figure in the HTML.

(i.e., 0.07) was the value observed immediately after the transport experiments (which was substantially smaller than the original sand content of the mixture). A total of 13 experimental runs were performed. During the bed load experiments, we have observed vortices generated in the sampling tube and efficient trapping and conveying of bed load sediment to the collector. Because no sediment was added at the upstream end of the flume, to avoid the armoring effect, for most runs bed load samples were taken for the first 10 minutes, which appeared to be sufficient for a representative evaluation of the bed load transport rates but not so long as to considerably reduce the sand content in the bed surface. For several other runs with high transport rates, sampling was stopped when the sediment collector was full.
The samples were dried, sieved, and weighed for evaluating the fractional transport rates.

[22] Sand and gravel transport rates were then correlated to the corresponding excess shear stress, $\left(\tau_{0}-\tau_{c s}\right)$ or $\left(\tau_{0}-\tau_{c g}\right)$, for quantifying the effects of flow intensity and sand content on bed load transport, where $\tau_{0}$ was determined with (5) for a given $Q$, the values of $\tau_{c s}$ and $\tau_{c g}$ were evaluated with the two-fraction entrainment approach (Figure 1) for a given $f_{s}$. On the basis of the regression, we obtained a set of equations for predicting the sand and gravel transport rates:

$$
\begin{array}{ll}
q_{b s}=6.64 \times 10^{-4} f_{s}^{3.05}\left(\tau_{0}-\tau_{c s}\right)^{3.33} & \text { for } f_{s} \leq 0.2 \\
q_{b s}=4.9 \times 10^{-6}\left(\tau_{0}-\tau_{c s}\right)^{3.33} & \text { for } f_{s} \geq 0.2 \\
q_{b g}=1.06 \times 10^{-5}\left(\tau_{0}-\tau_{c g}\right)^{3.19} & \text { for } f_{s} \leq 0.4
\end{array}
$$

where $q_{b s}$ and $q_{b g}$ are in $\mathrm{kg} / \mathrm{m} / \mathrm{s} ; \tau_{c s}, \tau_{c g}$, and $\tau_{0}$ are in Pa. Equation (6) reveals that the proportion of sand or gravel appears in the bed load equation if that fraction constitutes the minor portion of the bed sediment. For a gravel bed $\left(f_{s}<\right.$ 0.2 ), the sand fraction is the minor portion, thus $f_{s}$ is explicitly included in $q_{b s}$ to account for the small amount of sand available for transport. As such, (6a) is applicable to a limiting condition $q_{b s} \rightarrow 0$ as $f_{s} \rightarrow 0$. However, for $f_{s} \geq 0.2$, the effect of $f_{s}$ on $q_{b s}$ becomes less explicit. In this case, $f_{s}$ indirectly affects $q_{b s}$ through its influence on $\tau_{c s}$, as indicated by (6b). On the other hand, the gravel fraction does not constitute the minor portion of a transitional or gravel bed $\left(f_{s} \leq 0.4\right)$. Thus the proportion of gravel $f_{g}(=1-$ $f_{s}$ ) is not present in $q_{b g}$, but is implicitly included in the $\tau_{c g}$ term of $(6 \mathrm{c})$. The proposed bed load relations along with the observed data are shown in Figure 7a. It is demonstrated that the measured $q_{b s}$ for $f_{s}>0.2$ (i.e., 0.25 and 0.32 ) can be collapsed into a single curve, which obviously deviates from that for $f_{s}<0.2$ (i.e., 0.07 ), while the measured $q_{b g}$ for $f_{s}<0.4$ (i.e., all data) can be represented by a single bed load relation. These results appear to support our reasoning for partition of the bed load equations. The predictions generally agree well with the measurements, with $R^{2}=0.86$ and 0.66 for (6b) and (6c), respectively. However, the measured $q_{b s}$ for $f_{s}=0.07$ is very small and does not appear to increase with the shear stress as predicted by (6a), suggesting that there is negligible sand available for transport. Although fit of (6a) to the observed data is not demonstrated, the condition of small $f_{s}$ is associated with negligible sand transport, such that accuracy in predicting these tiny sand transport rates is not of great practical importance. To explore the variation between $q_{b s}$ and $q_{b g}$, a diagram showing the values of $q_{b s} /\left(q_{b s}+q_{b g}\right)$ is presented in Figure $7 \mathrm{~b}$, where it is revealed that $q_{b s} /\left(q_{b s}+q_{b g}\right)$ for three different $f_{s}$ consistently decreases with the increase of $\tau_{0}$, implying that the increase of $q_{b g}$ with $\tau_{0}$ is faster than that of $q_{b s}$. The decrease of $q_{b s} /\left(q_{b s}+q_{b g}\right)$, or equivalently increase of $q_{b g}$, with $\tau_{0}$ is more substantial for $f_{s}>0.2$. As revealed by $(6 \mathrm{c})$, this is attributable to the effects induced by both the increase of $\tau_{0}$ and decrease of $\tau_{c g}$. In addition, at a given $\tau_{0}$, the value of $q_{b s} /\left(q_{b s}+q_{b g}\right)$ is greater for the higher value of $f_{s}$, which, according to $(6 \mathrm{~b})$ and $(6 \mathrm{c})$, is primarily due to the 

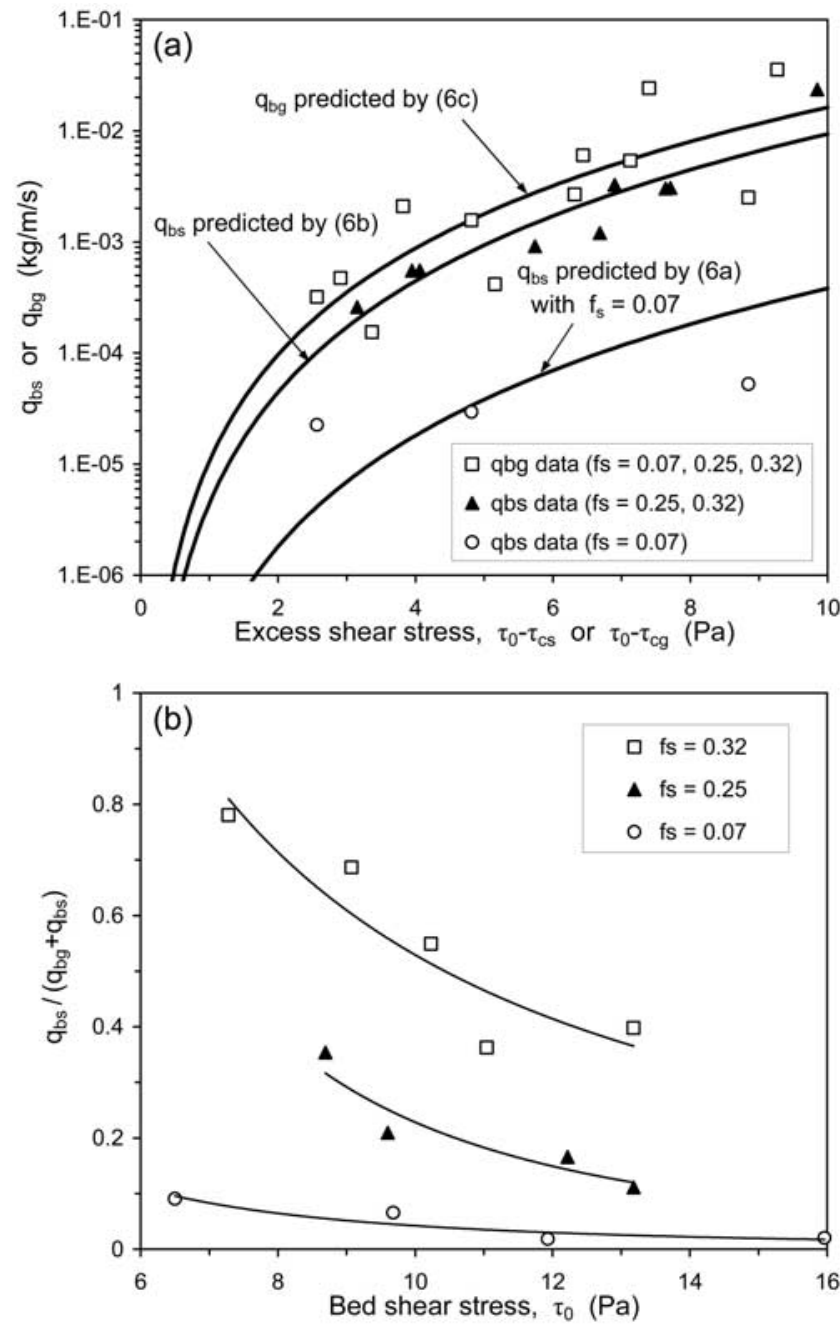

Figure 7. (a) Gravel and sand transport rates as a function of excess shear stress. For the measured bed load data, bed shear stress was estimated with (5), based on the given $Q$; critical shear stress was evaluated with the two-fraction entrainment approach shown in Figure 1, based on the given $f_{s}$. (b) Variations of $q_{b s} /\left(q_{b s}+q_{b g}\right)$ with bed shear stress for different values of sand content.

lower thresholds for entrainment. These results demonstrate that the sand content has a significant effect on the entrainment and thus transport of sediment in gravel-bed rivers.

\subsection{Flushing Flow Experiment}

[23] To verify the numerical simulation results, we conducted a flushing flow experiment to observe the depth flushing process and evolutions of bed composition and elevation. To carry out this experiment, the middle portion of the gravel bed was replaced with a 2.5-m-long gravel/ sand mixture reach (Figure 3 ) of which the sand content was 0.32 (grain size distribution of this mixture is shown in Figure 5a). The magnitude of flushing flow was set to be $0.068 \mathrm{~m}^{3} / \mathrm{s}$, for which an estimate of $\tau_{0}=13.3 \mathrm{~Pa}$ can be obtained with (5). Selection of this flow discharge was based on the previous tests producing sufficient gravel entrainment. For observational and computational purposes, the gravel/sand mixture reach was designated as subreaches 1 to 3 (each $\sim 0.83 \mathrm{~m}$ in length) from upstream to downstream, respectively. The flushing flow experiment was lasted for 7 hours, a duration estimated from a preliminary numerical simulation for which sufficient sand removal could be achieved in three subreaches.

[24] To investigate the temporal and spatial variations of the surface and subsurface sand proportions, we used the acrylic cylinders shown in Figure $6 \mathrm{~b}$ to sample the bed material at the specified time during the flushing flow experiment. The sampling cylinders were $6 \mathrm{~cm}$ in height and $9 \mathrm{~cm}$ in diameter. In each subreach, the sampling cylinders were inserted into the bed (with the opening facing down) following the sequence indicated in Figure 8. The inserted cylinders were left therein until the end of the experiment so that the composition of the bed material in the cylinder could be maintained. A total of 9 cylinders were inserted into the bed in each subreach, respectively at $0,0.5,1,1.5,2,3,4,5.5$, and 7 hours after the onset of flushing flow release. The locations to insert these cylinders were arranged in an alternating manner in order to average out the spatial difference of sand content within a subreach. Each of the sampling cylinders was fully inserted into the bed (by trying to make the least disturbance to the bed) such that the top surface of the cylinder was even with the bed level. A few gravels were glued on the top surface to reduce the effect of a sudden change in local roughness. As the flushing flow experiment was finished, water was drained and the sampling cylinders were taken out from the bed. In each sampling cylinder, the upper and lower halves (thickness $=3 \mathrm{~cm} \approx D_{84}$ ) of the bed material were separately collected, sieved, and weighed. By doing so, we obtained a set of data concerning the temporal and spatial variations of $f_{s}$ and $f_{s s}$ that could be used to compare with the simulation results.

[25] For each subreach, the bed level observations were made at nine equally spaced locations illustrated in Figure 8. At the specified time during the flushing flow experiment, we observed the bed levels at these locations through the sidewall and took the average of these values to be the mean bed level of a subreach. This procedure was intended to demonstrate the reach-scale variation trend of bed level by eliminating the fluctuation of bed elevation within a subreach. No bed elevation data were taken after 4 hours

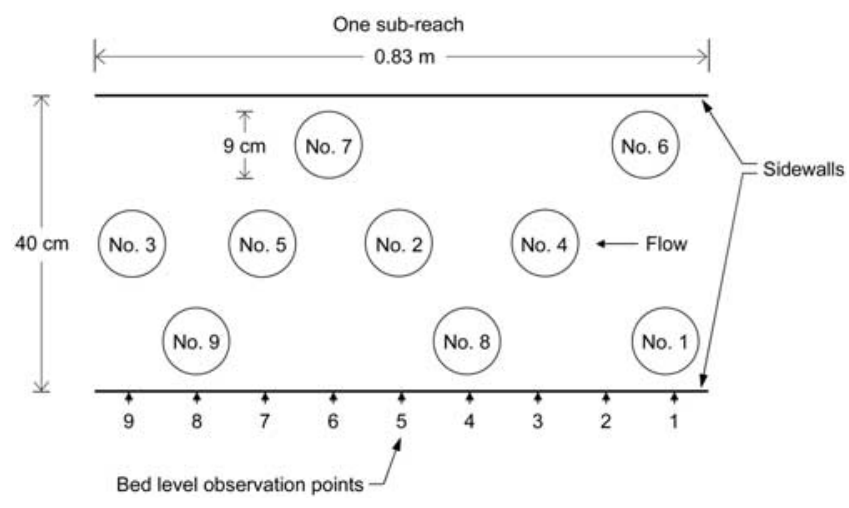

Figure 8. Locations for bed material sampling and bed level observation within a subreach. The sampling cylinders were inserted into the bed following the indicated sequence. 
Table 1. Model Parameters and Simulation Conditions

\begin{tabular}{|c|c|c|}
\hline & Description & Value \\
\hline \multicolumn{3}{|c|}{ Parameter } \\
\hline$D_{g}$ & median size of gravel fraction & $12 \mathrm{~mm}$ \\
\hline$d_{s}$ & median size of sand fraction & $1.3 \mathrm{~mm}$ \\
\hline$n_{g}$ & porosity of gravel & 0.33 \\
\hline$n_{s}$ & porosity of sand & 0.2 \\
\hline$\rho_{s}$ & density of sediment & $2650 \mathrm{~kg} / \mathrm{m}^{3}$ \\
\hline$L_{s}$ & $\begin{array}{l}\text { surface layer thickness } \\
\quad\left(=D_{84}\right)\end{array}$ & $26 \mathrm{~mm}$ \\
\hline$L_{s s}$ & $\begin{array}{l}\text { subsurface layer thickness } \\
\quad\left(=D_{84}\right)\end{array}$ & $26 \mathrm{~mm}$ \\
\hline$t_{e x}$ & exchange time & $15 \mathrm{~min}$ \\
\hline \multirow[t]{2}{*}{$L$} & subreach length & $0.83 \mathrm{~m}$ \\
\hline & $\begin{array}{l}\text { simulation reach length } \\
\text { ( } 3 \text { subreaches })\end{array}$ & $2.5 \mathrm{~m}$ \\
\hline \multirow[t]{2}{*}{$\Delta t$} & time step & $1 \mathrm{~s}$ \\
\hline & simulation time & 7 hours \\
\hline \multicolumn{3}{|c|}{ Hydraulic condition } \\
\hline$Q$ & flushing flow discharge & $0.068 \mathrm{~m}^{3} / \mathrm{s}$ \\
\hline$\tau_{0}$ & bed shear stress & $13.3 \mathrm{~Pa}$ \\
\hline \multicolumn{3}{|c|}{ Initial Condition } \\
\hline$f_{s}$ & surface sand proportion & 0.32 \\
\hline$f_{s S}$ & subsurface sand proportion & 0.32 \\
\hline \multicolumn{3}{|c|}{ Boundary condition } \\
\hline$q_{b g, i n}$ & $\begin{array}{l}\text { upstream gravel inflow } \\
\text { to subreach } 1\end{array}$ & $0.00387 \mathrm{~kg} / \mathrm{m} / \mathrm{s}$ \\
\hline$q_{b s, i n}$ & $\begin{array}{l}\text { upstream sand inflow } \\
\text { to subreach } 1\end{array}$ & none \\
\hline
\end{tabular}

because the inserted sampling cylinders had notably disturbed the bed level. On the other hand, an armor layer was observed on the gravel bed upstream of the mixture reach, leading to a ceased gravel transport in the upstream reach. To simulate a scenario that the upstream gravel bed reach is sufficiently long to provide a steady gravel supply to the mixture reach, throughout the flushing experiment we supplied gravels from the upstream end as a $3 \mathrm{~kg}$ slug once every 30 minutes (this quantity of gravel feed was determined with (6c) for $\tau_{0}=13.3 \mathrm{~Pa}$ and $\left.f_{s}=0\right)$ ). Therefore we obtained another set of data regarding the evolutions of bed level (bed degradation) in the three subreaches subjected to a steady gravel supply from upstream.

\section{Numerical Simulation}

[26] The proposed sediment routing algorithm was implemented to simulate the flushing process observed in the flume experiment. Flow was not simulated and shear stress was calculated with (5) for the given $Q\left(=0.068 \mathrm{~m}^{3} / \mathrm{s}\right)$. The model parameters are summarized in Table 1 , where most of the parameter values have been described in earlier sections. The numerical simulation was carried out for the three subreaches in the gravel/sand mixture reach, each with $L=0.83 \mathrm{~m}$. The exchange time $t_{e x}$, representing the duration required to produce complete entrainment of the bed surface, was taken to be 15 minutes based on a qualitative observation that all grains on the bed surface appeared to be entrained about once every 15 minutes. The time step $\Delta t$ used in the computation was 1 second, less than 1/25,000 of the flushing flow duration (= 7 hours). The preflushing sand proportion in the mixture reach was 0.32 for both the surface and subsurface layers. The upstream boundary condition was specified as a clean gravel bed supplying gravels with a constant rate $(=0.00387 \mathrm{~kg} / \mathrm{m} / \mathrm{s})$ estimated from $(6 \mathrm{c})$. No sand was conveyed to the simulation reach, but the gravel and sand in a subreach could be entrained and transported through the surface layer. The sand and gravel transport rates were evaluated with (6) using the $f_{s}$ value in that subreach. The change of bed level was first computed with (3). The changes of sediment storage in the surface and subsurface layers were than evaluated by taking into account the upward sand flux from subsurface and the effect of bed degradation. At the end of each time step, the values of $f_{s}$ and $f_{s s}$, the cumulative bed level change, and the sediment transport rates (including $q_{b s}, q_{b g}$, and $q_{s u b, s}$ ) for each subreach were updated and recorded.

\section{Results and Discussion}

\subsection{Surface Sand Proportion}

[27] The simulated evolutions of surface sand proportion in the three subreaches, along with the experimental data, are shown in Figure 9. Generally speaking, the simulation results are in good agreement with the observations. The declines of surface sand proportion were relatively fast in the first 2 hours or so but became slower thereafter. The effect of sand cleansing progressively propagated from upstream to downstream. For example, the simulated $f_{s}$ value in subreach 1 reached 0.2 (the boundary between the transitional and framework-supported beds) after 0.73 hours of flushing, while it took 1.6 and 2.4 hours, respectively, for subreaches 2 and 3 to reach the same level. At the end of the flushing flow experiment, the surface sand proportions observed in these subreaches have reduced to the values between 0.06 and 0.1. Shown in Figure 10 are two photographs that demonstrate the preflushing and postflushing states of the bed surface in subreach 2 . The abundant light-colored fine sediment observed in the preflushing bed $\left(f_{s}=0.32\right)$ was a clear contrast to the postflushing bed $\left(f_{s}=0.07\right)$. These results reveal that a significant amount of fine sediment was removed from the bed surface. Another feature of the depth flushing, i.e., removal of sand from the subsurface, is presented in the following section.

\subsection{Subsurface Sand Proportion}

[28] The evolutions of subsurface sand proportion in the three subreaches are demonstrated in Figure 11, where the

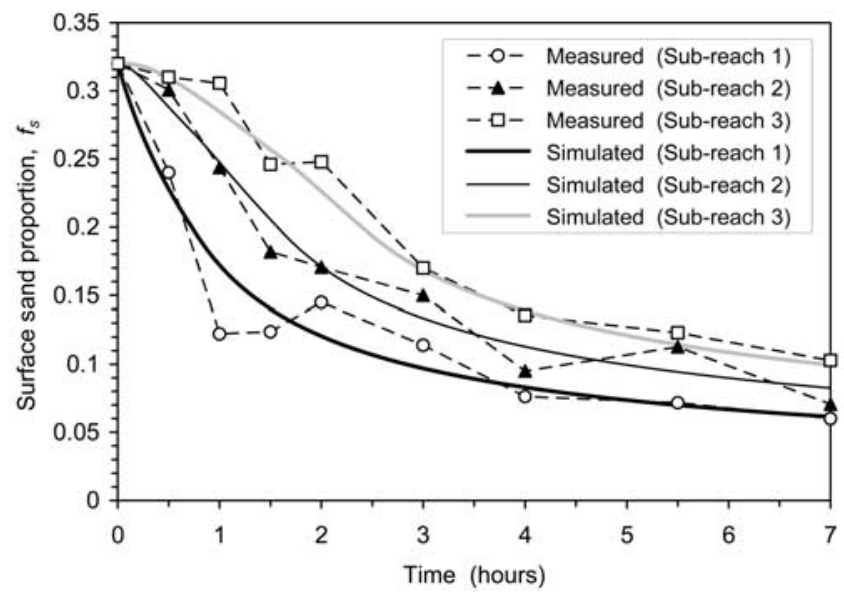

Figure 9. Simulated and measured evolutions of surface sand proportion in three subreaches of the gravel/sand mixture reach. 

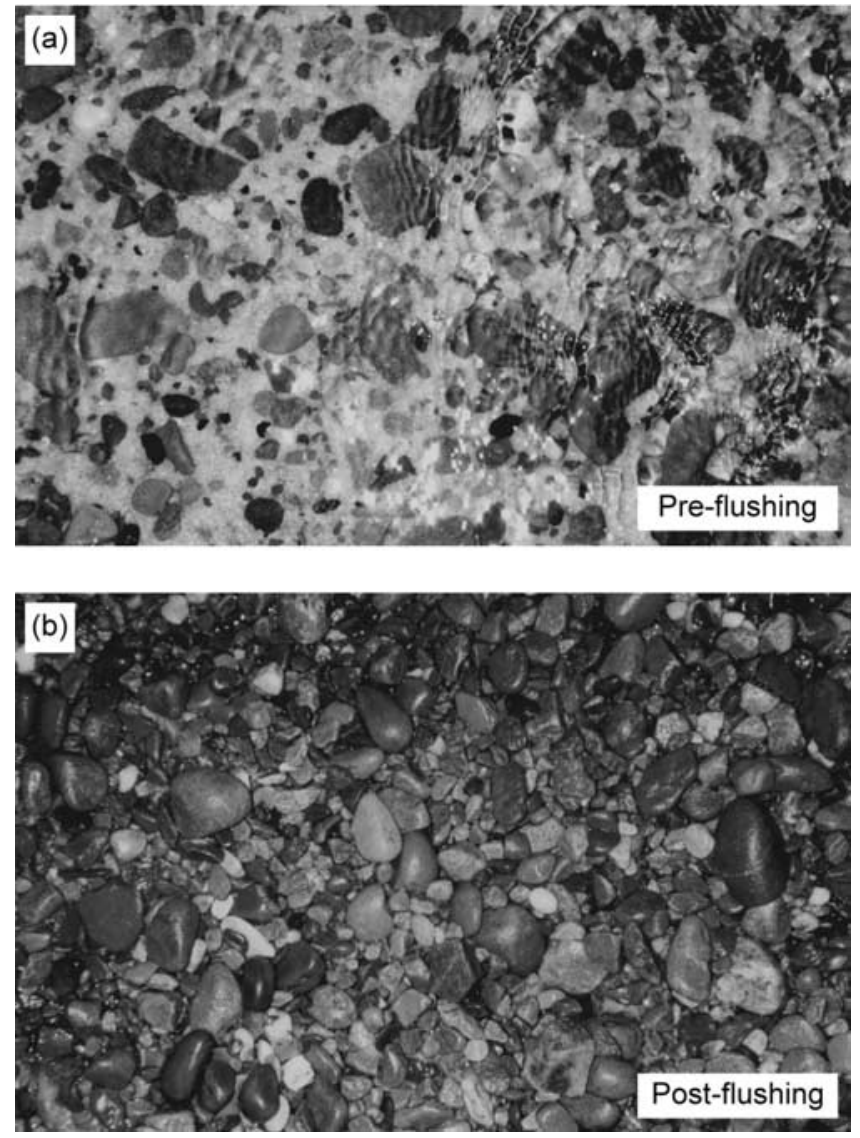

Figure 10. Demonstration of (a) preflushing and (b) postflushing states of the bed surface. The photographs (each covers a $30 \times 20 \mathrm{~cm}$ area) were taken at subreach 2 before and after 7 hours of flushing. Abundant light-colored sand shown in the preflushing bed surface $\left(f_{s}=0.32\right)$ was a clear contrast to the postflushing bed surface $\left(f_{s}=0.07\right)$. See color version of this figure in the HTML.

simulation results coincide well with the observations. The temporal and spatial variation patterns of $f_{s s}$ are essentially similar to those of $f_{s}$ shown in Figure 9, only that $f_{s s}$ declined slower than $f_{s}$. The average decline (in three subreaches) at the end of the flushing duration was $14 \%$ greater in the surface layer. As revealed by (1), this difference between $f_{s s}$ and $f_{s s}$ is the driving force for the upward sand flux from subsurface, which plays an important role in removal of sand from the subsurface. To investigate this effect, a trial simulation was executed by neglecting the upward sand entrainment. The results revealed that the flume experiment could not be adequately simulated without an upward sand flux from the subsurface. Because the upward sand flux from subsurface cannot be directly observed, the only recourse is to develop a numerical simulation model and compare the results with experiments. The experimental results presented here confirm the operation of a process that has only been hypothesized and show that (1) provided a credible model for this upward entrainment.

\subsection{Sediment Transport Rates}

\subsubsection{Sand Transport Rate}

[29] Figure 12 demonstrates the temporal variations of the simulated sediment transport rates in three subreaches. It is shown in Figure 12a that the sand transport rate declined very fast in the beginning but then approached asymptotically to a vanishing small value. The decline was slower in the downstream subreach. The decrease of sand transport rate with time was essentially a result of the temporally declining value of $f_{s}$ as shown in Figure 9. The simulated $f_{s}$ values in subreaches $1-3$ reduced to 0.2 at $0.73,1.6$, and 2.4 hours, respectively, thereafter the equation used to evaluate $q_{b s}$ was switched from (6b) to (6a). In Figure 12a, no obvious breaks in slope were observed, implying that a smooth transition between (6b) and (6a) has occurred. For $f_{s}$ values valid for $(6 \mathrm{~b}), \tau_{c s}$ increases with the decrease of $f_{s}$ (Figure 1), the calculated $q_{b s}$ values decrease with $f_{s}$ because of the reduced excess shear stress. However, for $f_{s}$ values valid for $(6 \mathrm{a}),\left(\tau_{0}-\tau_{c s}\right)$ remains constant, the calculated $q_{b s}$ values decrease with $f_{s}$ because of the reduced sand availability. The varying influences of $f_{s}$ on (6a) and (6b) could have resulted in the $q_{b s}$ curves with considerably different shapes. The smooth transitions shown in Figure 12a indicate that the partition scheme employed in the prediction of bed load transport rates might be a reasonable one.

\subsubsection{Gravel Transport Rate}

[30] The simulated evolutions of gravel transport rate are demonstrated in Figure $12 \mathrm{~b}$, where the $q_{b g, \text { out }}$ values declined rapidly at the beginning of the flow release. However, once the $f_{s}$ value reached 0.2 , the $q_{b g \text {,out }}$ value would remain invariant because $\tau_{c g}$ was constant for $f_{s} \leq$ 0.2 (Figure 1). This constant $q_{b g, \text { out }}$ was identical to the gravel supply rate from the upstream clean gravel reach, indicating that a balance between gravel inflow and outflow was first achieved in subreach 1 , and then proceeded to subreaches 2 and 3 . Once an equilibrium state was reached in a subreach, neither the storage of gravel nor the bed elevation would change thereafter.

[31] The equilibrium state of gravel transport can be further explored with the sediment-supply hypothesis [Dietrich et al., 1989], which demonstrates that a coarse surface layer develops in a gravel-bed river when sediment supply is less than the local transport capacity [Lisle et al., 1993, 2000; Buffington and Montgomery, 1999]. Here this quantitative model is extended to explain the coarsening of bed surface as a response to a supply of coarser-grained

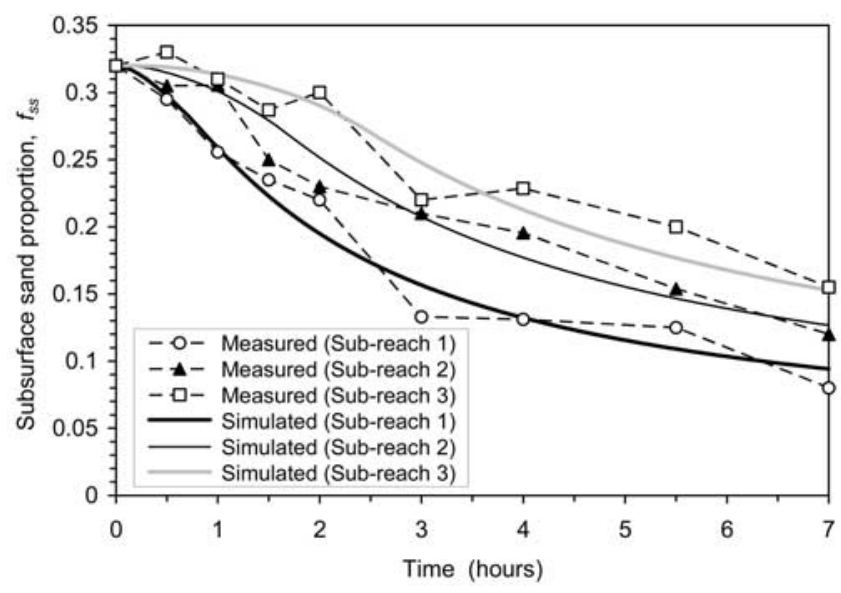

Figure 11. Simulated and measured evolutions of subsurface sand proportion in three subreaches of the gravel/sand mixture reach. 


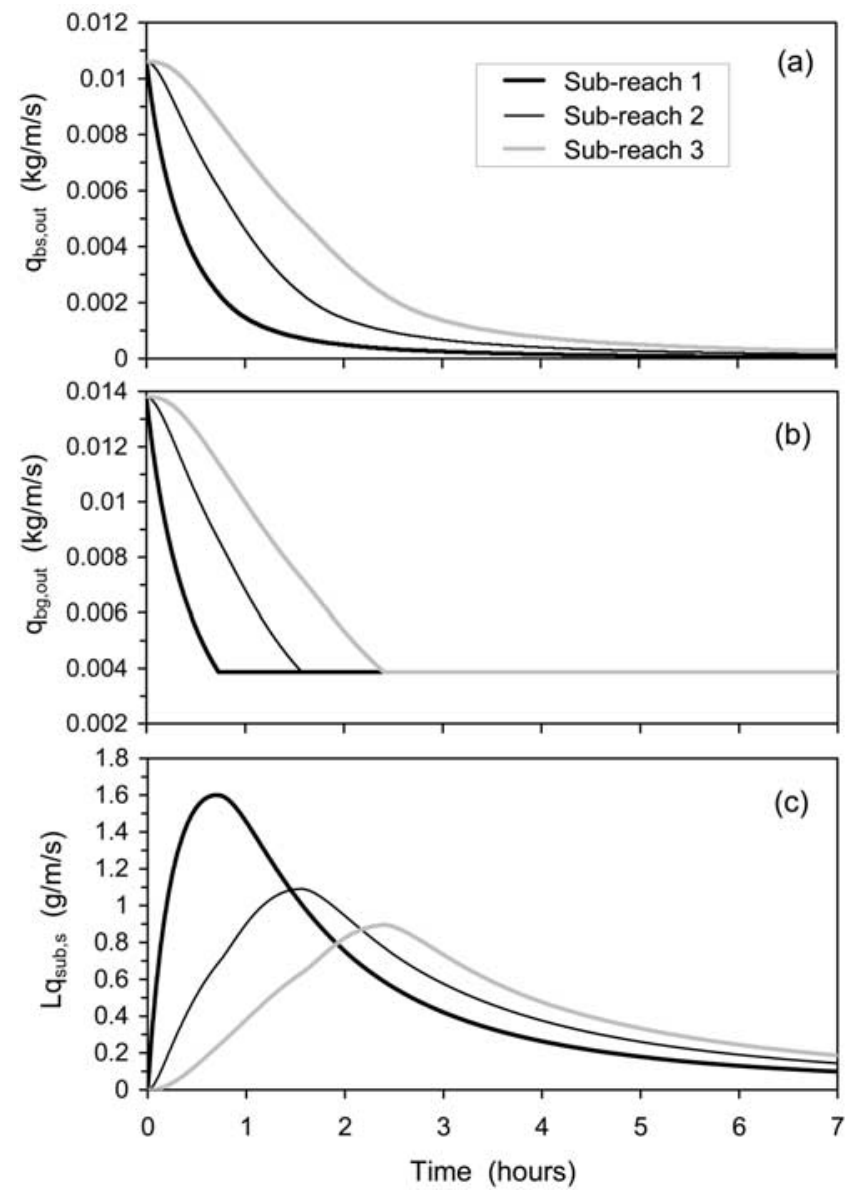

Figure 12. Simulated temporal variations of (a) sand transport rate, (b) gravel transport rate, and (c) subsurface sand entrainment rate in three subreaches of the gravel/sand mixture reach.

material, i.e., the upstream boundary condition imposed in the simulation and experiment. With (6c), a dimensionless gravel transport parameter $q^{*}$, defined as the ratio of observed gravel transport rate $q_{b g, o}$ to upstream gravel supply rate $q_{b g, s}$, is formed as

$$
q^{*}=\frac{q_{b g, o}}{q_{b g, s}}=\left(\frac{\tau_{0}-\tau_{c g, o}}{\tau_{0}-\tau_{c g, s}}\right)^{3.19}
$$

where $\tau_{c g, o}$ is critical shear stress of the gravels observed at bed surface; $\tau_{c g, s}$ is critical shear stress of the gravels in the upstream. For $f_{s}<0.2, \tau_{c g}$ is directly proportional to the median gravel size (Figure 1). As such, $\tau_{c g, o}$ and $\tau_{c g, s}$ can be expressed as a simple function of $D_{50, o}$ and $D_{50, s}$, respectively, where $D_{50, o}$ is median gravel size observed at bed surface, $D_{50, s}$ is median gravel size in the upstream. Accordingly, (7) can be modified as

$$
q^{*}=\left[\left(\frac{\tau_{0}}{\tau_{c g, s}}-\frac{D_{50, o}}{D_{50, s}}\right) /\left(\frac{\tau_{0}}{\tau_{c g, s}}-1\right)\right]^{3.19}
$$

An equilibrium state is reached as $q_{b g, o} \rightarrow q_{b g, s}$, leading to $q^{*} \rightarrow 1$ and $D_{50, o} \rightarrow D_{50, s}$, the latter implies that the surface composition of the observed mixture reach will eventually become comparable with that of a purely gravel bed (see the textural evolution demonstrated in Figure 10). This analysis reveals that the response of a gravel-sand bed to the flushing flow may be viewed as the coarsening of bed surface induced by a steady gravel supply. Evolution of bed composition is commonly associated with the development of an equilibrium gravel transport.

\subsubsection{Upward Sand Entrainment from Subsurface}

[32] The simulated evolutions of upward sand entrainment, $L q_{s u b, s}$, are shown in Figure $12 \mathrm{c}$, where the upward sand flux was multiplied by $L$ to be consistent in dimensions. The upward sand entrainment rate was initially equal to zero but attained the maximum shortly after the onset of flushing flow release, and then decreased slowly. The rise and fall were less drastic for a downstream subreach. The downstream propagation of the maximum upward sand entrainment is evident. This downstream propagation of the maximum upward sand entrainment implies that the sand cleansing effect also propagated downstream in the subsurface.

\subsection{Bed Level Change}

[33] The simulated and observed evolutions of mean bed levels in three subreaches are shown in Figure 13, where the cumulative bed level changes are demonstrated. The error bars attached to the measured mean bed level illustrate the maximum and minimum observed values. The simulation results coincide reasonably well with the observed mean trend and generally fall in the observed high-low bounds. The bed elevation remained invariant once the equilibrium gravel transport was reached. The simulated equilibrium degradation depths in subreaches $1-3$ were $1.1,1.7$, and $1.8 \mathrm{~cm}$, respectively. The greater degradation depth in the downstream was primarily due to the longer time to reach equilibrium. The difference between the equilibrium degradation depths in subreaches 1 and $2(=0.6 \mathrm{~cm})$ was more notable than that between subreaches 2 and $3(=0.1 \mathrm{~cm})$. With the upstream sand inflow to subreaches 2 and 3 , the surface sand proportions (Figure 9) and thus the gravel

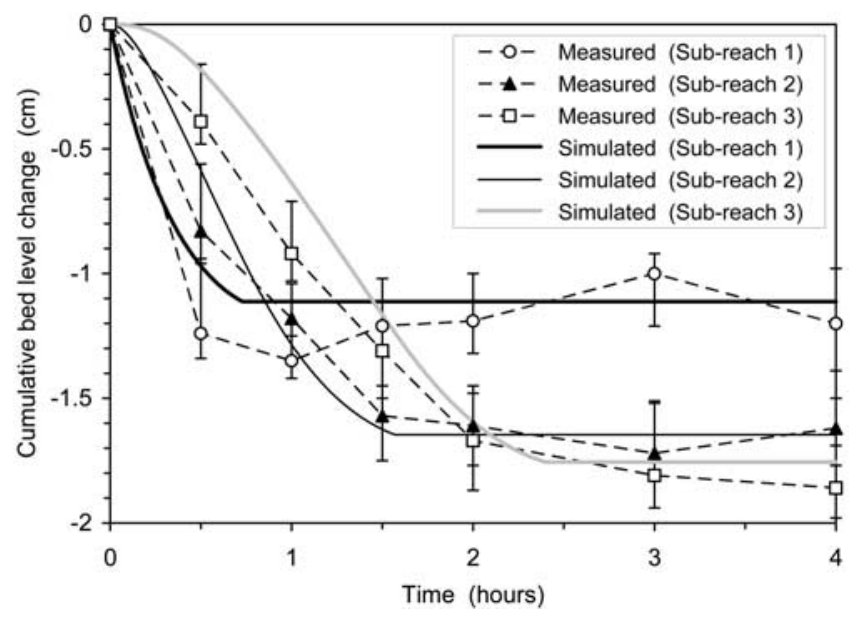

Figure 13. Simulated and measured evolutions of bed level change in three subreaches of the gravel/sand mixture reach. The error bars attached to the measured mean bed level represent the maximum and minimum observed values. 
transport rates (Figure 12b) in subreaches 2 and 3 would be relatively higher than those in subreach 1 . Consequently, the equilibrium degradation depths in subreaches 2 and 3 were close to each other but deviated from that in subreach 1 . It should be noted that the different degradation depths in subreaches 1-3 would result in changes in bed slope and thus increases in shear stress from that calculated with (5), with the shear stresses in subreaches 1 and 3 the greatest and smallest, respectively. These differences in shear stress would lead to different equilibrium transport rates in subreaches $1-3$ and eventually recover the bed slope toward the original value. However, in this study the change of bed level was only observed for 4 hours (due to the notable disturbances caused by the sampling cylinders), thus no sufficient data are available to verify the effect of such changes. The proposed model can be restructured in the future to incorporate the slope into the equation for calculating shear stress. The degradation of channel bed also reveals that the loss of gravel is associated with the release of flushing flows, implying that the optimum flushing flow is expected to be a compromise among the released water volume, total gravel loss, and flushing efficiency.

\section{Summary and Conclusions}

[34] In this paper we present a sediment routing model used for simulation of the gravel-sand bed response to flushing flows. The proposed model employs a two-fraction entrainment approach to evaluate the critical shear stresses of sand and gravel as a function of sand content. An active two-layer framework is adopted to outline the sediment transport system associated with the depth flushing process. Within this framework bed load is transported in the surface layer; the subsurface sand is removed with a mechanism of upward entrainment. The two-layer treatment also allows incorporation of subsurface sand into the surface at a rate proportional to bed degradation; change of bed elevation is estimated from the continuity equation of sediment in the surface layer. Then based on the mass conservations of sediment, the surface and subsurface sand proportions are progressively updated at each time step.

[35] To provide a test of the proposed model, we conducted a flushing experiment to observe the evolutions of bed composition (i.e., surface and subsurface sand proportions) and bed elevation. The simulation results are in good agreement with the observations. These results reveal that the effect of sand cleansing propagated downstream in both the surface and subsurface layers. The upward sand flux from subsurface rapidly attained the maximum and decayed more slowly. Sand and gravel transport rates both declined fast in the beginning, but the gravel transport eventually reached equilibrium. The equilibrium degradation depth increased downstream, which would however lead to changes in bed slope and shear stress, and thus in equilibrium transport rate (although not really observed in this study). For the simulated scenario, it is shown that the response of channel bed to the flushing flow may be viewed as the coarsening of bed surface induced by a steady upstream gravel supply.

[36] The primary advance represented by this work is incorporation of the idea that sand content has a direct effect on the entrainment thresholds and thus transport rates of both sand and gravel. An important result of the numerical simulation of the flushing experiment is that we noted that flume results could not be adequately simulated without an upward sand flux from the subsurface, confirming and providing an experimental support for a process that has only been hypothesized. While the results presented herein imply a potential application of the proposed model to the planning of flushing flows, more research and field data are needed before the model can be practically used in the field. First of all, verification of the simulation results should be done to test the model's performance using field data. The simulation results, including the evolutions of bed composition (preferably both surface and subsurface sand content) and bed level elevation at different locations, should be verified with the field observations. To do that, the parameters and components of the model, such as the size distribution of bed material, porosities and densities of gravel and sand, maximum depths of gravel and sand entrainment, flow-transport relations, and relation between flow and exchange timescale are required. The verified model can then be used to evaluate various flushing options in terms of the flushing efficiency (i.e., the required flushing duration to achieve the specified bed quality), released water volume, and total gravel loss. The tradeoffs between these outcomes of the multiobjective system can be quantitatively analyzed using the simulation results. On the basis of the tradeoff analysis, the feasible (or preferred) flushing options can be determined. However, the simulation model presented in this work is subjected to certain assumptions and limitations, which include the constant flow release, uniform flow in both the longitudinal and lateral directions, and that the change of bed slope is not incorporated into the prediction of bed shear stress. In addition, the upstream boundary condition of no sand input and the initial condition of uniform sand content in the entire simulation reach have led to monotonically increasing bed degradation along the channel. These are obviously simplifications of the complexity in natural gravel-bed rivers, where a sequence of pools (either natural or constructed) might act as the source or sink of fine sediments. The transport and deposition of sediment resulting from such site characteristics would be different from the scenarios simulated in the present work. These are the potential issues to be addressed in future studies to extend the applicability of the proposed model.

\footnotetext{
Notation

$C_{u} \quad$ upward entrainment constant.

$D_{g}$ median grain size of gravel fraction.

$D_{50, o}$ median gravel size observed at bed surface.

$D_{50, s}$ median gravel size in the upstream.

$D_{84}$ grain size of framework gravel for which $84 \%$ is finer.

$d_{s}$ median grain size of sand fraction.

$d_{84}, d_{90}$ grain size of bed material for which $84 \%$ and $90 \%$ is finer.

$f_{g}$ proportion of gravel in bed surface.

$f_{s}$ proportion of sand in bed surface.

$f_{s s}$ proportion of sand in bed subsurface.

$H$ bed level elevation.

$L$ length of a channel reach.

$L_{a}$ thickness of active layer.
} 
$L_{s}$ thickness of surface layer.

$L_{S S}$ thickness of subsurface layer.

$M_{s s}$ mass of sand in unit-area subsurface layer.

$n_{g}$ porosity of framework gravel.

$n_{s}$ porosity of sand matrix.

$Q$ flow discharge.

$q_{b g}$ gravel transport rate (mass/width/time).

$q_{b g, o}$ observed gravel transport rate.

$q_{b g, s} \quad$ upstream gravel supply rate.

$q_{b s}$ sand transport rate (mass/width/time).

$q_{\text {sub,s }}$ upward sand flux from the subsurface (mass/area/ time).

$q_{T}$ total bed load transport rate.

$q^{*}$ dimensionless gravel transport parameter defined in (7).

$R^{2} \quad$ coefficient of determination.

$t$ time.

$t_{e x}$ exchange time.

$u$ flow velocity at elevation $z$.

$u_{*} \quad$ bed shear velocity $=\sqrt{\tau_{0} / \rho}$.

$x$ distance in streamwise direction.

$z$ elevation from bed level.

$z_{0}$ virtual zero-velocity elevation.

$\Delta$ roughness height.

$\Delta H$ change of bed elevation.

$\Delta t$ time step.

$\gamma$ specific weight of water.

$\gamma_{s}$ specific weight of sediment.

$\tau_{c g}$ critical shear stress for gravel.

$\tau_{c g, o}$ critical shear stress of gravel observed at bed surface.

$\tau_{c g, s} \quad$ critical shear stress of gravel in the upstream.

$\tau_{c s}$ critical shear stress for sand.

$\tau_{0}$ bed shear stress.

$\tau_{c}^{*}$ dimensionless critical shear stress (or Shields stress).

$\tau_{c g}^{*}$ dimensionless critical shear stress for gravel.

$\lambda$ porosity of surface layer.

$\kappa$ von Karman constant.

$\rho$ density of water.

$\rho_{s}$ density of sediment.

[37] Acknowledgments. This research was supported, in part, by the Council of Agriculture (90-AD-2.2-F-01) and National Science Council (NSC-89-2313-B-002-246) of the Republic of China. The pioneering work of P. R. Wilcock has inspired us to carry out this study. We appreciate WRR reviewers for their constructive comments on an earlier manuscript of this paper. We are very grateful to the Associate Editor for his insightful suggestions for improving the clarity of the presentation.

\section{References}

Beschta, R. L., and W. L. Jackson, The intrusion of fine sediments into a stable gravel bed, J. Fish. Res. Board Can., 36, 204-210, 1979.

Bradley, C., and D. G. Smith, Meandering channel response to altered flow regime: Milk River, Alberta and Montana, Water Resour. Res., 20, 1913-1920, 1984.

Buffington, J. M., and D. R. Montgomery, Effects of sediment supply on surface textures of gravel-bed rivers, Water Resour. Res., 35, 3523-3530, 1999.

Collier, K. J., Effects of flow regulation and sediment flushing on instream habitat and benthic invertebrates in a New Zealand river influenced by a volcanic eruption, River Res. Appl., 18, 213-226, 2002.

Costa, J. E., A. J. Miller, K. W. Potter, and P. R. Wilcock (Eds.), Natural and Anthropogenic Influences in Fluvial Geomorphology, Geophys. Monogr. Ser., vol. 89, AGU, Washington, D. C., 1995.

Cui, Y., G. Parker, and C. Paola, Numerical simulation of aggradation and downstream fining, J. Hydraul. Res., 34, 185-204, 1996.
Dietrich, W. E., J. W. Kirchner, H. Ikeda, and F. Iseya, Sediment supply and the development of the coarse surface layer in gravel-bedded rivers, Nature, 340, 215-217, 1989.

Diplas, P., and G. Parker, Pollution of gravel spawning grounds due to fine sediment, Proj. Rep. 240, St. Anthony Falls Hydrol. Lab., Univ. of Minn., Minneapolis, 1985

Ferguson, R. I., M. Church, and H. Weatherly, Fluvial aggradation in Vedder River: Testing a one-dimensional sedimentation model, Water Resour. Res., 37, 3331-3347, 2001.

Habersack, H. M., and J. B. Laronne, Bed load texture in an alpine gravel bed river, Water Resour. Res., 37, 3359-3370, 2001.

Hirano, M., River bed degradation with armoring, Proc. Jpn. Soc. Civ. Eng., $195,55-65,1971$

Hoey, T. B., and R. Ferguson, Numerical simulation of downstream fining by selective transport in gravel bed rivers: Model development and illustration, Water Resour. Res., 30, 2251-2260, 1994.

Holly, F. M., and J. L. Rahuel, New numerical/physical framework for mobile-bed modeling, part I: Numerical and physical principles, J. Hydraul. Res., 28, 401-416, 1990a.

Holly, F. M., and J. L. Rahuel, New numerical/physical framework for mobile-bed modeling, part II: Test applications, J. Hydraul. Res., 28, 545-564, 1990b.

Julien, P. Y., Erosion and Sedimentation, Cambridge Univ. Press, New York, 1998.

Kondolf, G. M., and P. R. Wilcock, The flushing flow problem, Water Resour. Res., 32, 2589-2599, 1996.

Lisle, T. E., F. Iseya, and H. Ikeda, Response of a channel with alternate bars to a decrease in supply of mixed-size bedload: A flume experiment, Water Resour. Res., 29, 3623-3629, 1993.

Lisle, T. E., J. M. Nelson, J. Pitlick, M. A. Madej, and B. L. Barkett, Variability of bed mobility in natural, gravel-bed channels and adjustments to sediment load at local and reach scales, Water Resour. Res., 36 , $3743-3755,2000$.

Milhous, R. T., Sediment transport in a gravel-bottomed stream, Ph.D. thesis, Oreg. State Univ., Corvallis, 1973.

Milhous, R. T., Numerical modeling of flushing flows in gravel-bed rivers, in Gravel-Bed Rivers in the Environment, edited by P. C. Klingeman et al., pp. 579-608, Water Resour. Publ., Highlands Ranch, Colo., 1998 .

Miller, R. W., Flow Measurement Engineering Handbook, McGraw-Hill, New York, 1996.

Nezu, I., and H. Nakagawa, Turbulence in Open-Channel Flows, A.A. Balkema, Brookfield, Vt., 1993.

Nikora, V. I., D. Goring, I. McEwan, and G. Griffiths, Spatially averaged open-channel flow over rough bed, J. Hydraul. Eng., 127, 123-133, 2001.

Parker, G., and A. J. Sutherland, Fluvial armor, J. Hydraul. Res., 28, $529-$ $544,1990$.

Parker, G., C. Paola, and S. Leclair, Probabilistic Exner sediment continuity equation for mixtures with no active layer, J. Hydraul. Eng., 126, $818-$ 826, 2000.

Petts, G. E., Impounded Rivers, John Wiley, Hoboken, N. J., 1984.

Proffitt, G. T., Selective transport and armoring of non-uniform alluvial sediments, Res. Rep. 80/22, Dep. Civ. Eng., Univ. of Canterbury, Christchurch, New Zealand, 1980.

Rahuel, J. L., F. M. Holly, J. P. Chollet, P. J. Belleudy, and G. Yang, Modelling of riverbed evolution for bedload sediment mixtures, J. Hydraul. Eng., 115, 1521-1542, 1989.

Raupach, M. R., R. A. An tonia, and S. Rajagopalan, Rough-wall turbulent boundary layers, Appl. Mech. Rev., 44, 1-25, 1991.

Reiser, D. W., Sediment in gravel bed rivers: Ecological and biological considerations, in Gravel-Bed Rivers in the Environment, edited by P. C. Klingeman et al., pp. 199-228, Water Resour. Publ., Highlands Ranch, Colo., 1998.

Reiser, D. W., M. P. Ramey, and T. A. Wesche, Flushing flows, in Alternatives in Regulated River Management, edited by J. A. Gore, and G. E. Petts, pp. 91-135, CRC Press, Boca Raton, Fla., 1989.

Robinson, A. R., Vortex tube sand trap, Trans. Am. Soc. Civ. Eng., 127, $391-425,1962$.

Tacconi, P., and P. Billi, Bed load transport measurements by the vortextube trap on Virginio Creek, Italy, in Sediment Transport in Gravel-Bed Rivers, edited by C. R. Thorne, J. C. Bathurst, and R. D. Hey, pp. 583616, John Wiley, Hoboken, N. J., 1987.

van Niekerk, A., K. R. Vogel, R. L. Slingerland, and J. S. Bridge, Routing of heterogeneous sediments over movable bed: Model development, J. Hydraul. Eng., 118, 246-261, 1992. 
Walker, K. F., and M. C. Thoms, Environmental effects of flow regulation on the lower River Murray, Australia, Reg. Rivers Res. Manage., 8, $103-$ $119,1993$.

Ward, J. V., and J. A. Stanford (Eds.), The Ecology of Regulated Streams. Proceedings of the First International Symposium on Regulated Streams, Plenum, New York, 1979.

Whiting, P. J., and W. E. Dietrich, Boundary shear stress and roughness over mobile alluvial beds, J. Hydraul. Eng., 116, 1495-1511, 1990.

Wilcock, P. R., Estimating local bed shear stress from velocity observations, Water Resour. Res., 32, 3361-3366, 1996.

Wilcock, P. R., Two-fraction model of initial sediment motion in gravel-bed rivers, Science, 280, 410-412, 1998.

Wilcock, P. R., A. F. Barta, C. C. Shea, G. M. Kondolf, W. V. G. Matthews, and J. Pitlick, Observations of flow and sediment entrainment on a large gravel-bed river, Water Resour. Res., 32, 2897-2909, 1996a.

Wilcock, P. R., G. M. Kondolf, W. V. G. Matthews, and A. F. Barta, Specification of sediment maintenance flows for a large gravel-bed river, Water Resour. Res., 32, 2911-2921, 1996b.

Wilcock, P. R., S. T. Kenworthy, and J. C. Crowe, Experimental study of the transport of mixed sand and gravel, Water Resour. Res., 37, 3349$3358,2001$.
Williams, G. P., and M. G. Wolman, Downstream effects of dams on alluvial rivers, U.S. Geol. Surv. Prof. Pap., 1286, 1984.

Wohl, E. E., Mountain Rivers, Water Resour. Monogr. Ser., vol. 14, pp. 1-3, AGU, Washington, DC, 2000.

Wu, F.-C., Modeling embryo survival affected by sediment deposition into salmonid spawning gravels: Application to flushing flow prescriptions, Water Resour. Res., 36, 1595-1603, 2000.

Wu, F.-C., and C.-F. Wang, Effect of flow-related substrate alteration on physical habitat: A case study of the endemic river loach Sinogastromyzon Puliensis (Cypriniformes, Homalopteridae) downstream of Chi-Chi diversion weir, Chou-Shui Creek, Taiwan, River Res. Appl., 18, 155-169, 2002 .

Y.-J. Chou and F.-C. Wu, Department of Bioenvironmental Systems Engineering, National Taiwan University, Taipei 106, Taiwan. (fcwu@hy. ntu.edu.tw) 